\title{
A revolução venezuelana: chavismo e bolivarianismo
}

\author{
RAPHAEL SEABRA \\ Doutorando em Sociologia (Universidade de Brasília) \\ Brasília, Brasil \\ raphaelseabra@hotmail.com
}

\begin{abstract}
Resumo Uma das transformações mais significativas desde o início do governo bolivariano em 1999 é que a participação política, mais do que mera formalidade, tem se convertido em realidade. O termo "chavismo" aparece muitas vezes como síntese descritiva da totalidade desses processos de mudança social, fato que tem lhe rendido a insígnia populista. Apesar de importante para a compreensão da revolução bolivariana, ao centrar suas atenções sobre o "fenômeno Chávez", ignora-se a importância das relações entre mobilizações e organizações sociais para impulsionar e sustentar o processo. O objetivo deste artigo é delimitar as distâncias concretas entre chavismo, bolivarianismo e populismo. Para isso, parte-se da avaliação das transformações recentes Venezuela, tanto as que envolvem os instrumentos políticos dirigidos por Chávez, como também das classes subalternas que começam a se manifestar politicamente ao longo da década de 1990.
\end{abstract}

Palavras-chave: Chavismo, bolivarianismo, populismo, Venezuela

\section{Introdução}

$\mathrm{D}$ esde a eleição de Hugo Chávez, em 1999, se gestaram mudanças e rupturas profundas no esquema político e democrático venezuelano, dando forma ao processo conhecido como Revolução Bolivariana da Venezuela. Claro que existem diferenças quanto à interpretação do grau de profundidade, ou às características das mudanças e rupturas em andamento, e à própria natureza real dessa revolução. Nesse sentido, o termo "chavismo" aparece muitas vezes como síntese descritiva da totalidade desses processos de mudança político-social, fato que lhe tem rendido a insígnia populista. Apesar de importante para a compreensão da revolução bolivariana, ao centrar suas atenções no "fenômeno Chávez", ignora-se a importância das relações entre manifestações, mobilizações e organizações sociais para impulsionar e sustentar o processo. Mesmo que Chávez se constitua em uma figura imprescindível de continuidade, durante momentos dramáticos de seu governo e decisivos para o processo, seja a reviravolta de 11 de abril de 2002, seja a recuperação e cogestão de empresas estratégicas a partir de 2008, essas organizações e os setores populares foram determinantes tanto para sua sustentação como para o aprofundamento da revolução.

Uma das transformações mais significativas desde o início do governo bolivariano, em 1999, é a de que a participação política mais do que mera formalidade tem-se convertido em realidade. Esse fato contribui para a politização e para o fortalecimento da organização dos setores populares. Buscamos através da avaliação das transformações internas, tanto dos instrumentos políticos dirigidos por Chávez como também das organizações sociais que começam a se manifestar durante a década de 1990, estabelecer critérios capazes de delimitar as 
distâncias concretas entre chavismo, bolivarianismo e populismo.

\section{De vítimas a sujeitos de poder? As classes subalternas em movimento e o bolivarianismo}

Ao contrário do que se pensa, o recurso à herança político-intelectual dos próceres da pátria venezuelana não é exclusivo do projeto da Quinta República:

Quando há um legado ideológico ou um corpo de pensamento comparativamente muito estruturado e sistemático, como ocorre no caso de Simón Bolívar, se dá a oportunidade de transcender o símbolo utilizando esse legado para compor, respaldar ou suprir programas de ação política de todo gênero. (Carrera Damas, 2005, p. 15)

Todavia a referência ao legado bolivariano pode realizar-se tanto através da adoção a-histórica, envolta na simples admiração e exaltação, como também na adoção historicamente reexaminada, na atualização de seu projeto emancipatório. No primeiro caso trata-se do culto a Bolívar

como uma oferta ideológica compensatória do decepcionante balanço da abolição da monarquia e ruptura do nexo colonial, conquistados na Venezuela mediante uma crudelíssima e prolongada guerra que foi essencialmente civil e que, por isso, deixou inapagáveis sequelas de ódio e rancores no seio da classe dominante. (Carrera Damas, 2005, p. 24-25)

Em síntese, o culto a Bolívar surge da necessidade - compartilhada pela classe dominante venezuelana - de restabelecer o domínio e a estrutura políticoeconômica da sociedade, cuja possibilidade se faz possível à sombra do libertador.

No segundo caso, do bolivarianismo, cuja elaboração tem início nos anos 1960, quando o movimento guerrilheiro venezuelano começa a se afastar da ortodoxia soviética e inicia o reexame do papel histórico e social de Simon Bolívar, releitura continuada pelo MBR-200 (Gott, 2004). O bolivarianismo pode ser definido pelos pontos essenciais do programa e da atuação histórica de Bolívar, que ainda têm grande validade contemporânea. É o caso de sua constância e perseverança revolucionárias, de sua compreensão da necessidade de união de todos os revolucionários para alcançar o triunfo da revolução, de sua orien- tação para uma independência plena e soberana, de suas advertências constantes contra o perigo por parte do expansionismo dos EUA. Torna-se precursor do anti-imperialismo, e seu programa de solidariedade latino-americana, com conteúdo revolucionário e progressista, objetiva alcançar um novo equilíbrio na balança internacional (Zeuske, 1985, p. 18-19). Em suma, o bolivarianismo se fundamenta no resgate e na continuidade do projeto de emancipação venezuelano das oligarquias político-econômicas que reproduzem a estrutura dependente, contra a subordinação do país à influência de agentes do imperialismo e a distribuição radical do poder político. Refere-se assim às condições de realização da segunda emancipação.

Portanto, a atualização à esquerda do bolivarianismo foi - e ainda é - de grande importância, pois mais do que reativar o nacionalismo, o anti-imperialismo, o integracionismo regional e distinguir-se da tradição folclórica dos "donos do poder", rompe-se igualmente com a atribuição apriorística do sujeito da emancipação social. A forma de integração venezuelana ao mercado mundial, pautada na exportação petroleira, mesmo que tenha desenvolvido algumas indústrias de capital intensivo reunidas em torno desta produção, o fez em detrimento das indústrias de bens de capital, uma vez que o "grosso" da produção nacional encontra sua realização no mercado externo. A classe trabalhadora venezuelana desenvolveu-se sobre as bases do desemprego, subemprego e superexploração do trabalho. Isso é evidente pelo fato de que "em princípios da década de 1980 essa situação evidenciava que $90 \%$ das exportações da Venezuela eram geradas por apenas 3\% da mão-de-obra" (Nicanoff; Stratta, 2008, p. 5).

Isso significa que, mesmo possuindo peso político significativo, o reduzido operariado petroleiro não é capaz por si de converter-se em sujeito exclusivo da emancipação, sem levar em conta a fragmentação e a hierarquização que define a classe trabalhadora venezuelana. A renovação criativa do bolivarianismo demonstra que a fragmentação e a hierarquia no interior da classe trabalhadora não podem ser superadas somente pela socialização da produção, mas sim em conformidade com a participação e distribuição radical do poder político.

Com exceção da guerrilha da década de 1960, a Venezuela não era reconhecida no continente como um país de grandes mobilizações e organizações sociais, como também não pertencia ao grupo de países em transição da ditadura à democracia. A mudança de consciência desencadeada pelo Sacudón ou Caracazo, em fevereiro de $1989,{ }^{1}$ claramente expressa no crescimento vertiginoso do número de reivindicações de rua e de paralisações de trabalhadores, demarca uma 
peculiar forma de relação e negociação entre os setores populares e o poder estatal, definida como "política de rua". O ambiente de deslegitimação das organizações sindicais, partidárias e estatais contribui para a natureza e forma específicas das manifestações populares. Assim, manifestações de rua de setores sociais distintos, como estudantes, camelôs, desempregados, funcionários públicos e habitantes de bairros médios e pobres, têm em comum o caráter reivindicativo de direitos violados ou negligenciados, apresentando-se como vítimas do Estado e enfatizando a apoliticidade das demandas (López-Maya, 2002).

A generalidade das movimentações das classes subalternas ao longo da década de 1990, ao construir suas demandas com base no discurso dos direitos cidadãos vitimados por um Estado rico e negligente, antes de reforçar a auto-concepção de sujeitos de poder, reforçou a auto-concepção de vítimas do poder. O caráter reivindicativo e fragmentado foram fatores que dificultaram a consolidação das manifestações para além da rua, em direção a outros espaços e canais de disputa político-hegemônicos mais sólidos como cooperativas, associações, sindicatos e partidos (López-Maya, 2002).

A mudança qualitativa da ação coletiva da concepção de vítimas do poder à concepção de sujeitos de poder começa a se transformar quando, após a posse de Chávez em 1999, têm início as discussões em torno da preparação da nova Carta Magna e se abrem espaços democráticos para a participação. Os movimentos sociais, partidos e organizações civis apresentaram cerca de 624 propostas à Assembleia Constituinte, sendo que mais da metade delas foram incorporadas ao texto constitucional (López-Maya, 2003; Ellner, 2008).

As modalidades de referendos previstas na Constituição de 1999 são parte dos elementos decisivos das vias de participação democrática, protagônica e popular da vida política do país. E levam adiante o princípio de que "o povo soberano deve se transformar no objeto e no sujeito do poder. Essa opção não é negociável para os revolucionários" (Chávez, 2007, p. 12). Por isso mesmo, é de suma importância que o processo bolivariano conserve a autonomia e a discussão com partidos, movimentos e organizações que compõem sua base, além de promover concretamente as circunstâncias normais de participação e protagonismo, e não somente representação.

Desde então, tendo em vista a existência contraditória entre o potencial popular e a deficiência organizativa, o governo bolivariano tem não só impulsionado tanto a organização de movimentos já existentes, mas também incentivado a criação dessas estruturas em comunidades menos organizadas. Em 2001, o modelo organizativo que fundou as bases do bolivarianismo, os Círculos Bolivarianos, é recriado com objetivos ampliados, que abrangem desde a difusão da nova Constituição, discussões políticas, formação de associações de bairros ou cooperativas de pequenos produtores, até grupos de mães. São estruturas que não possuem comando centralizado e nem se articulam permanentemente (Maringoni, 2004).

A promulgação das 49 Leis Habilitantes, em específico a Lei de Terras, reabriu o enfrentamento da questão agrária e da soberania alimentar pela via constitucional, fato que incentivou a organização da Frente Campesina Revolucionária Simón Bolívar, que, dada sua abrangência nacional, é, desde 2004, a Frente Nacional Campesino Ezequiel Zamora (FNCEZ). Do mesmo modo, formaram-se as Mesas Técnicas de Água (MTA), cujo objetivo central era a de, através do diálogo e da troca de experiências entre moradores das comunidades e técnicos, encontrar soluções para as graves deficiências no serviço de água potável e saneamento básico. Destacam-se também os Comitês de Terras Urbanas (CTU), que foram criados para regularizar os loteamentos urbanos nos bairros populares. Apesar de serem produto direto do Estado, têm sua representação eleita na comunidade (Lovera, 2008).

Uma das peculiaridades da revolução bolivariana é a combinação desigual entre o reivindicativo e o político por parte das classes subalternas e o incentivo direto ou indireto do Estado bolivariano à sua organização. Isso fica patente durante o golpe de abril de 2002, pois, enquanto as lideranças do MVR passavam a clandestinidade, foi desencadeada uma força social espontânea que não foi antecipada por nenhum intelectual. Enquanto centenas de milhares de habitantes dos barrios de Caracas mobilizados ocupam as ruas, rodeando quartéis, os meios de comunicação e o Palácio de Miraflores enfraquecem o golpe e fazem aflorar a enorme potencialidade das ações coletivas iniciadas tempos atrás (Nicanof; Stratta, 2008).

De modo semelhante, durante a greve patronal da Petróleos de Venezuela AS (PDVSA), em 2002, enquanto cerca de $80 \%$ dos altos funcionários da estatal cruzavam os braços, a mesma proporção de trabalhadores de menor salário continuou trabalhando, assumindo o controle dos locais de trabalho (Ellner, 2008, p. 49-58). Ao assumir o controle e impedir a sabotagem da empresa e do complexo industrial mais importante da Venezuela, com apoio da maioria do exército - que considerou tal atitude como um ataque à soberania nacional -, a classe trabalhadora venezuelana desloca historicamente a Confederação de Trabalhadores de Venezuela (CTV), central associada à oposição, e funda, em 2003, a União Nacional de Trabalhadores (UNT) como central autônoma e combativa (Nicanof; Stratta, 2008).

Após as ofensivas golpistas, o governo de Chávez tem atuado em várias frentes, visando ampliar 
sua base de sustentação. Faz parte desses esforços o lançamento das Missões Sociais, que inicialmente se propunham a solucionar as carências e problemas da população gerados pela paralisação petroleira de 2002-2003. Esses planos sociais promovem estruturas da administração pública paralelas às tradicionais e alcançam amplos setores populares, além de um terço dos setores médios da sociedade venezuelana. Segundo Lander (2007, p. 72), as missões têm como virtude "sua capacidade para saltar obstáculos burocráticos e chegar de forma direta e rápida aos setores mais excluídos da população", como também "boa parte destas missões se baseia na promoção dos processos organizativos nas comunidades como parte de seu desenho e execução". Como consequência, tem sido enorme seu impacto sobre as condições de vida das classes populares, e ainda mais ampla a diversidade de processos organizativos populares que tem contribuído para criar ou fortalecer todo o país.

Os Conselhos Comunais representam até o momento o maior esforço do governo bolivariano em organizar e incentivar a participação social. Eles seriam instâncias participativas, organizadas e articuladas dentro das próprias comunidades, para que estas exercessem diretamente a gestão de políticas públicas e projetos pautados nas necessidades e prioridades locais. Sua lógica participativa atravessaria diretamente os níveis estaduais e municipais, estabelecendo não só uma relação direta entre a organização comunitária e o governo federal, mas também os mecanismos para sua constituição. Assim, os trâmites para a formulação de projetos e obtenção de recursos exigiriam poucas mediações burocráticas. "Em poucos meses se gerou uma dinâmica de mudanças e expectativas que tiveram um importante efeito organizativo e mobilizador. Inclusive em setores de classe média de Caracas se criaram Conselhos Comunais", fortalecendo, portanto, "o tecido social nas comunidades e a cultura política da participação" (Lander, 2007, p. 77-78).

A revolução bolivariana enfrenta, portanto, não somente as ofensivas da oposição, mas também os conflitos dentro de suas fileiras, entre os que desejam aprofundar a revolução e aqueles que perfilam como uma nova elite. A nacionalização da empresa Sidor (Siderúrgica do Orinoco) em 2008, "só foi possível sobre os cimentos de uma organização de base capaz de confrontar com a direção da empresa privada Sidor e conduzir o Estado a uma nacionalização de uma área estratégica com peso decisivo da co-gestão operária em sua administração" (Nicanoff: Stratta, 2008, p. 14). Isto incentivou a nacionalização de alguns setores da indústria alimentar, da Companhia Anônima Nacional de Telefones da Venezuela (CANTV) e do Banco de Venezuela. Esse fato, porém, suscita o debate acerca tipo de sociedade socialista que se pretende; ou seja, se as empresas nacionalizadas passarão ao controle autogestionário dos trabalhadores ou se permanecerão sob o controle majoritário estatal. Em outras palavras, se as condições permitirão superar a identificação histórica entre propriedade pública e propriedade estatal (Nicanoff; Stratta, 2008).

O fato mais expressivo das últimas décadas é a combinação desigual entre o "reivindicativo e o político, sem separações mecânicas de um plano sobre outro", o que notoriamente revela "que a quase totalidade dos movimentos sociais existentes se fundam depois de 1999 e, sobretudo a partir de 2002. Isto marca tanto a relevância do processo, como seu caráter difuso, mutante e instável" (Nicanoff; Stratta, 2008, p. 13). Nesse sentido, pode-se afirmar que a organização social em torno dos Círculos Bolivarianos, das Mesas Técnicas de Água, das Missões Sociais e dos Conselhos Comunais está em consonância com o bolivarianismo, na medida em que almeja, de fato, transformar o povo em objeto e sujeito do poder.

\section{Do 4-F aos motores do socialismo: entre o "fenômeno Chávez" e o chavismo}

Os eventos desencadeados pelo Sacudón representam o ponto de declive irreversível da política puntofijista que regia a sociedade venezuelana desde 1958. Sua dramaticidade expressa uma verdadeira crise política, social e econômica, de maneira que "a história contemporânea da Venezuela começa realmente com esse acontecimento fundamental" (Gott, 2004, p. 72). O aspecto fundamental desse evento foi o de revelar as debilidades do sistema político-social, suas dificuldades em retificar suas condutas ou responder à recessão econômica e ao empobrecimento crescente da população. O Sacudón contribuiu profundamente para a mudança de consciência entre os setores populares, bem como criou o ambiente para as revoltas militares dos anos seguintes, conferindo a esses setores "uma percepção coletiva do presente e do futuro que era distinta a até então prevalecente" (López Maya, 2002, p. 18).

A visibilidade nacional do Movimento Bolivariano Revolucionário-200 (MBR-200) como movimento político ocorre logo após a derrota do levante militar em 4 de fevereiro de 1992 (4-F). Mesmo levando-se em conta todos os riscos de quebra do regime democrático, o levante militar foi muito positivo para o movimento bolivariano. De um lado, a tentativa de levante "teve o significado simbólico de buscar um rompimento com um sistema que não resolvia os problemas da população". De outro, o levante gerou "heróis claramente visíveis pela opinião 
pública", com destaque para o tenente-coronel Hugo Chávez Frías (Maringoni, 2004, p. 144-146).

O "fenômeno Chávez" surge pela primeira vez após sua rendição ao realizar um breve discurso de um minuto e doze segundos em rede nacional, no qual convoca seus companheiros de levante a baixar as armas. Nesse sentido, o "fenômeno Chávez" exercia um impacto distinto sobre a sociedade. Para os “donos do poder", representava o caráter autoritário e militarista do levante, como se este fosse simplesmente a atitude irresponsável e isolada do tenente-coronel; para as "classes populares", o levante conferia visibilidade às insatisfações sociais de anos anteriores, capturando sua imaginação coletiva e a possibilidade de transformação do sistema vigente.

Desde então, o MBR-200 se transforma numa organização sociopolítica de alcance nacional. É nesse momento que surgem os Círculos Bolivarianos como estrutura organizacional primária que frequentemente organizava assembleias locais para discutir política, círculos de estudo e formação ideológica. Através dos Círculos Bolivarianos era disseminado o Projeto $\mathrm{Na}$ cional Simon Bolívar, cujo postulado central era: "o povo soberano deve se transformar no objeto e no sujeito do poder. Essa opção não é negociável para os revolucionários" (Chávez, 2007, p. 12). Com o crescimento do apoio e da participação popular no movimento bolivariano, em princípios de 1997, o MBR-200 decide participar com candidato próprio das eleições presidenciais de 1998. Para a disputa eleitoral registra-se o partido Movimento Quinta República (MVR), que reflete a cautela dos líderes do movimento "sobre o simbolismo de cada ação política, e o nome que eles escolheram para a nova organização não era exceção" (López-Maya, 2003, p. 83).

Existe uma grande diferença entre o MBR-200 como organização política e o MVR como partido político. Enquanto o primeiro era uma estrutura horizontal e descentralizada cujo objetivo primário era a formação e conscientização política de seus membros, o segundo era uma estrutura vertical e centralizada que se propunha exclusivamente à conquista eleitoral, distanciando-se de qualquer tipo de formação ideológica. Em que pese essa diferença, o MVR era um movimento demasiado heterogêneo, que só não excedia a heterogeneidade da coalizão que levaria Hugo Chávez à presidência em 1999: o Polo

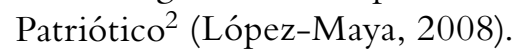

Os desequilíbrios e as diferenças ideológicas de setores e partidos que compunham a coalizão colocavam, desde então, "Chávez como único capaz de mediar ou acalmar as diferenças internas, o que reforçava o caráter imprescindível do líder e imprimia a ação do governo às diretrizes ideológicas deste" (López-Maya, 2008, p. 59). Sendo assim, se o chavismo surge logo após o levante militar, de maneira a destacar a figura e a atribuir a responsabilidade ao ex-tenente-coronel, esse fenômeno ressurge em novas bases devido à heterogeneidade e às disputas internas do MVR como partido eleitoral. O chavismo encontra sua gênese na crescente centralidade de Chávez como figura de unidade e de direção imprescindível ao processo. Portanto, não causa espanto que em determinados momentos o chavismo se confundisse e até mesmo se chocasse com o bolivarianismo, entendido como a totalidade do processo em marcha.

Um dos grandes marcos da construção alternativa à Quarta República foi a redação e a decisão em referendo, em dezembro de 1999, do novo texto constitucional. Apesar de garantir a propriedade privada, inova com a promoção do conceito de democracia participativa e protagônica (RBV, 1999, art. 62). Com a introdução de um conjunto de modalidades participativas, mesmo sem substituir a representação, tratava-se de ampliar o poder dos movimentos e organizações sociais e de um corretivo do poder desmesurado exercido pela partidocracia. ${ }^{3}$

É consensual que as 49 Leis Habilitantes representam a primeira inflexão da revolução bolivariana e que tanto o golpe de Estado de 11 de abril de 2002 como o segundo Paro Patronal em 2002-2003 exprimiram a reação da oposição a essa inflexão, e que a disputa hegemônica em torno da substituição do sistema puntofijista não havia se concluído. Esses eventos também evidenciaram as debilidades organizativas do governo bolivariano, que após sua conversão em partido eleitoral contava com reduzidos militantes dentro do órgão institucional (Lopez-Maya, 2008).

No desenrolar do processo, encerrada - temporariamente - a via golpista, a oposição recorre à via institucional e realiza o referendo revogatório em 15 de agosto de 2004. Assim, depara-se novamente com o "fenômeno Chávez", pois esse referendo representava mais do que a redução entre o a favor ou contra Chávez, porém a confirmação da legitimidade e continuidade do processo. Nesse sentido, mesmo

2. O Polo Patriótico reunia o Movimento Quinta República, o Partido Pátria Para Todos (PPT), o Partido Comunista Venezuelano (PCV), o Movimento Al Socialismo (MAS) e o Movimento Eleitoral do Povo (MPE).

3. Ellner (2010, p. 80) denomina tais mudanças democráticas como "democracia radical", que "sustentada pelas formulações de Jean-Jacques Rousseau, coloca ênfase no governo da maioria ao contrário dos direitos das minorias. [...] Um componente-chave da democracia radical é a mobilização de massa, que por sua vez conduzem ao empoderamento, incorporação e 'aprendizado político' na parte dos formalmente excluídos". 
se tratando de apoiar diretamente a presidência de Hugo Chávez, o referendo está além de sua liderança, podendo ser caracterizado como o desfecho da polarização iniciada em 2002 e como ponto inicial da mudança de qualidade da revolução bolivariana.

Tal mudança de qualidade é notável a partir da reeleição de Chávez em 2006, quando são anunciadas algumas tarefas em torno da construção do Socialismo do Século XXI. Entre estas, destacam-se a criação do Partido Socialista Unido de Venezuela (PSUV), para agrupar as forças políticas de apoio ao processo; o projeto de Reforma Socialista da Constituição e o empoderamento do poder popular por meio dos Conselhos Comunais ${ }^{4}$ (CC).

As debilidades do MRV, engessado como partido eleitoral, o crescente número de movimentos de base bolivariana e a virada ao socialismo colocavam grandes desafios ao processo revolucionário. A consciência de tais desafios tornou consensual dentro do movimento bolivariano a necessidade de um instrumento político capaz de não só organizar uma força eleitoral, mas também organizar e preparar as forças transformadoras para a batalha de ideias e a disputa política no interior da sociedade venezuelana. Assim, em dezembro de 2006, era anunciada a formação do PSUV (Partido Socialista Unido de Venezuela), cujo objetivo central era o de construir uma base partidária sólida e organizada, estabelecendo a unidade complexa entre a liderança governista e a base social bolivariana (Monedero, 2007).

Para um processo revolucionário permeado desde sempre por uma conflituosa relação entre o reivindicativo e o político, a verticalidade que marcou a formação e construção do novo partido político socialista, automaticamente, "se traduziu em agressões, tensões e conflitos com o presidente ao longo de 2007" (López-Maya, 2008, p. 60). O novo partido socialista foi organizado da mesma maneira do MVR, com caráter de "urgência", pois seu objetivo imediato era o de aglutinar base eleitoral bolivariana suficiente para, através do Referendo de Reforma Constitucional, instituir pelo voto o socialismo. Assim foi determinada dissolução de todos os partidos dentro do PSUV; aqueles que se recusassem deveriam abandonar o governo. Se existia então o consenso sobre a necessidade de um novo instrumento político, não houve maiores discussões sobre seu programa e, mais uma vez, a unidade e a condução do novo partido convergiam na figura central de Chávez (López-Maya, 2008).

A proposta de Reforma Constitucional em 2007 expressava a vontade política de radicalizar o bolivarianismo, de projetar a sociedade venezuelana ao socialismo pela via institucional. Antes de representar a derrota do projeto de transformação social bolivariano, a derrota do Referendo de Reforma, de certo modo, representa a primeira derrota do chavismo. O episódio de 2007 teve como ponto positivo a reflexão sobre os caminhos e descaminhos do processo bolivariano, trazendo também à tona a divisão entre chavismo e bolivarianismo.

Mesmo que permeado pelo personalismo de Chávez, não é possível afirmar a cristalização definitiva dessa tendência nem a consolidação de seu controle sobre as organizações e movimentos de base. Antes da derrota em 2007, a dissidência e a crítica eram quase intoleráveis, de maneira que era comum catalogar as discordâncias como traição ao movimento. Era então comum: estigmatizar os aliados políticos como Partido Comunista da Venezuela ou o Pátria Para Todos, por não se dissolverem no PSUV; pressionar as forças sindicais e movimentos sociais que opunham resistência à perda de sua autonomia para formar os Conselhos Comunais; repreender organizações populares ou intelectuais que dissentiam das propostas e opiniões do presidente (Salazar, 2007). A tendência a atribuir a derrota a questões externas ao bolivarianismo tem dado lugar a discussões sobre questões internas, tais como a necessidade de respeito à pluralidade política, de despersonalização e desburocratização, com a abertura ao debate e à participação maior nas decisões do movimento.

Os dez anos de Revolução Bolivariana coincidiram, em fevereiro de 2009, com a vitória do "fenômeno Chávez" na decisão em referendo da emenda constitucional para reeleições presidenciais indefinidas. Apesar das acusações da oposição, isso não garante a reeleição indefinida de Hugo Chávez, mas possibilita que tal feito se realize enquanto se apresentar viável. O "fenômeno Chávez", portanto, é aqui definido como garantia de continuidade do processo revolucionário. Expõe, contudo, a continuidade de algumas debilidades do processo, sobretudo do chavismo, tais como: o excesso de personalismo que se gesta desde a formação eleitoral do MVR e a falta de lideranças e quadros para dar continuidade às transformações; o risco de regressão e desgaste da via democrática referendária pela redução das consultas à forma plebiscitária do ou a favor ou contra Chávez. Esse fato, em médio ou longo prazo, pode vir a restringir não somente a autonomia das organizações sociais, como também o pluralismo que tem sido um dos distintivos da processo bolivariano e talvez sua maior contribuição às lutas democráticas e de liberação no mundo (Salazar, 2007).

4. As tarefas prioritárias são sintetizadas na fórmula dos cinco grandes motores: a Lei Habilitante; a reforma socialista da Constituição; a educação popular; a nova geometria do poder; e a explosão revolucionária do poder comunal. 


\section{Chavismo como retorno do populismo?}

Dois corolários têm levado alguns estudiosos a definir o chavismo como um regime populista. De um lado, as condições de ascensão do chavismo ao poder, como resposta à crise institucional prolongada e à perda de representatividade dos partidos políticos tradicionais. De outro, as características da condução política nacional, fortemente personalizada, como é o caso do discurso nacionalista, antioligárquico e anti-imperialista, que frequentemente resgata os próceres da pátria com uma visão ético-moralista, identificando-se com eles: e, principalmente, a atração especial dos setores populares, estabelecendo com eles uma relação razoavelmente mediada por estruturas organizativas. Para esses estudiosos, o populismo chavista firma-se em determinada forma de discurso político (Parker, 2001; Laclau, 2006; Hawkins, 2009).

Para Parker (2001) e Laclau (2006), o populismo é um discurso político que pode trazer em seu bojo um enorme potencial transformador, embora repleto de contradições. Não se trata de atribuir ao populismo conotações pejorativas ou demagógicas,

trata-se de um discurso político que se distingue por interpelar e impregnar profundamente entre os setores populares, que por sua vez busca estimular um entusiasmo e um potencial de mobilização entre estes mesmos setores que abre perspectivas de profundas mudanças na sociedade. (Parker, 2001, p. 27-28)

Isto não significa que todo populismo seja, por si, bom, pois sua forma é capaz de se articular com diversos conteúdos políticos. Para Laclau (2006, p. 60), no caso venezuelano, "qualquer avanço demandava uma mudança de regime. Mas, para alcançá-lo, era necessário construir um novo ator coletivo de caráter popular. Ou seja, em nossa terminologia, não havia possibilidade alguma de mudança sem uma ruptura populista".

No entanto, a amplitude e a heterogeneidade ideológica da base social do governo chavista, conforme sugerem as evidências, leva a um desenvolvimento repleto de contradições, que "também explica o papel fundamental que leva o líder do movimento a mediar ou resolver essas contradições" (Parker, 2001, p. 34). Portanto, o que "constitui uma questão legítima é se há ou não uma tensão entre o momento da participação popular e o momento do líder, se o predomínio deste último não pode levar à limitação daquele" (Laclau, 2006, p. 60). "O êxito do projeto populista e as perspectivas de aprofundar seu potencial revolucionário" exigem a potencialização das organizações e movimentos de base bolivariana, de modo que se contornem as tendências personalistas e burocráticas da condução do processo. "Esta última consideração nos leva a fundar como problema as características do MVR como organização" (Parker, 2001, p. 37).

Para Hawkins (2009), o populismo é um discurso político maniqueísta e paranoico, uma vez que atribui à disputa uma dimensão moral e demagógica, além de crer num desfecho conspirativo oposicionista. Sua definição discursiva defende que o populismo "identifica o Bem como o desejo de união do povo e o Mal como a elite conspiradora". Nesse sentido, "a história não apenas procede em direção a algum conflito final, mas que este já havia chegado, e que não se poderia abster dessa luta". De um lado, as referências da retórica chavista aos próceres venezuelanos e à democracia demarcam o "bem"; de outro, suas críticas à oposição, ao imperialismo ou aos meios de comunicação privados demarcam o "mal" (Hawkins, 2009, p. 1042-1043). Este autor conclui: "Partidos e lideranças populistas estão quase sempre presentes em todos os países, mas eles tipicamente adquirem proeminência em momentos de crises e tendem a ser de curto prazo, um fenômeno cíclico". Portanto, através da mensuração do discurso, é possível demonstrar que "uma pequena percentagem de líderes altamente populistas contemporâneos (inclusive Chávez) e constata[r] que seus discursos são muito similares aos bem conhecidos populistas do passado" (Hawkins, 2009, p. 1056-1061).

Embora existam diferenças no sentido conferido ao discurso populista, a preocupação desse conjunto de autores recai notadamente sobre as relações entre líder e massa populista, sobre o elemento personalista que varia entre o carismático e o autoritário, de maneira que este se torna um traço permanente na história político-democrática latino-americana. Como se sugere ao longo deste texto, uma das peculiaridades da Revolução Bolivariana é a de que a politização das classes sociais em disputa não se efetiva nos moldes tradicionais - ou seja, através de sindicatos ou partidos classistas - e a de que a liderança de Chávez surge como elemento mediador e aglutinador, ora impulsionando, ora subordinando a participação popular.

Para alguns autores (Ianni,1991; Lynch, 2000; Weffort, 2003; Vilas, 2003), o populismo consistiu num modelo político-econômico vigente em quase toda a América Latina entre as décadas de 1920 e 1960. Tratava-se, portanto, da conjugação específica de elementos externos (como as crises dos países industrializados durante o período entre guerras, no período de 1914 a 1945, que se encerra com a hegemonia mundial dos EUA) e internos (como a industrialização de substituição de importações e diversificação produtiva, impulsionada por um Estado de cunho nacionalista e intervencionista). A condução 
populista fortemente personalizada (por exemplo: o varguismo e o peronismo) apoiava-se na abertura democrática, na mobilização de massas e na integração da classe trabalhadora, dentro de um esquema de articulação política multiclassista, que respondia aos interesses do capital industrial.

Quando esses autores recorrem ao populismo como discurso, terminam por confundir a "complexidade do fenômeno a algumas de suas 'partes' constitutivas". Como sugere Vilas (2003), "a mais frequente é a que se refere à personalização da liderança populista". Assim, o reducionismo discursivo

permite aos autores apresentar o populismo como uma opção permanente na política latino-americana com independência das configurações transformadas dos cenários históricos - ou seja, da configuração das classes e outros atores sociais, do desenvolvimento e orientações da organização econômica e dos processos de acumulação, da estrutural internacional de poder etc. (Vilas, 2003, p. 18-21)

Portanto, mais do que um ou outro elementos tomados à parte, parece claro que o populismo corresponde a um fenômeno historicamente localizado.

A referência à liderança política de Hugo Chávez e às iniciativas do governo é importante e, muitas vezes, incontornável, mas encerrar o processo de mudança na direção limita a percepção da totalidade concreta que sustenta a revolução bolivariana. No momento do levante militar em 1992, o chavismo parecia denotar a saturação das contradições no seio da sociedade venezuelana. O próprio Chávez (2007, p. 86), porém, já advertia sobre os riscos de tal redução, ao afirmar: "chamar de chavismo o fenômeno coletivo [...] significa menosprezar as capacidades de percepção das realidades que têm adquirido nosso povo em seu desenvolvimento histórico".

Ao mesmo tempo em que o governo amplia suas frentes de atuação, seja através dos Círculos, das Missões ou dos Conselhos, verifica-se o crescimento de movimentos, frentes populares e setores políticos. Esse crescimento não se deve somente ao incentivo e apoio estatal, que claramente demarca sua posição no interior da disputa hegemônica, mas às próprias contradições e enfrentamentos que se evidenciam durante o processo; ao contrário do que crê Hawkins (2009, p. 1044), mais do que simples paranoia do líder populista, basta o fato de que na Venezuela "é a direita que, aos olhos da população, representou a instabilidade e o desrespeito às leis definidas pela maioria" (Maringoni, 2009, p. 28).

No entanto, se se verificam avanços significativos na superação da formalidade democrática, não se torna visível o acompanhamento sistemático na socialização da produção. Na realidade, o setor capi- talista tem se desenvolvido muito mais rapidamente que o setor público e, apesar das nacionalizações, ainda controla amplamente a economia nacional. Tal fato poderia ser um claro indicativo da concepção genérica de progresso e desenvolvimento nacional, típica das políticas de alianças de classes populistas. Porém, isso se explica pela forma de utilização da renda petroleira. De um lado, os recursos provenientes da exploração de petróleo são redistribuídos socialmente, com a intenção de melhorar as condições de vida da maioria da população pobre, nos âmbitos das Missões, na construção de moradias, de infraestrutura urbana e meios de transporte coletivos. De outro lado, são distribuídas subvenções importantes às cooperativas e aos Conselhos.

Desse modo, o "setor capitalista se beneficia também largamente desses gastos governamentais, pois é quem domina, de longe, o banco, o comércio e a indústria alimentar" (Toussaint, 2009, p. 8). Os recursos redistribuídos pelo Estado à sociedade terminam por concentrar-se nos bolsos dos capitalistas, pois são estes que controlam o sistema bancário nacional, a indústria alimentar, as cadeias de comércio e distribuição, os quais lucram amplamente com as importações com um tipo de câmbio muito favorável. Ademais, a fim de evitar maiores contendas com a desapropriação direta da propriedade capitalista, as nacionalizações têm sido levadas a cabo através do pagamento de indenizações de recompra. A continuidade e o aprofundamento do processo dependem, portanto, da modificação da tática de transição ao socialismo e de socialização da produção, pois a simples redistribuição da renda petroleira, por mais que satisfaça algumas das necessidades das classes subalternas, sugere efeito contrário ao reforçar o setor capitalista.

\section{Considerações finais}

A eleição de Hugo Chávez em 1999 dá início a mudanças e rupturas profundas no esquema político e democrático da Venezuela. Desde então, o termo "chavismo" aparece muitas vezes como síntese descritiva da totalidade dos processos de mudança político-social.

Este texto buscou demonstrar que, dentre algumas peculiaridades do processo bolivariano, destaca-se a mudança qualitativa dos movimentos das classes subalternas. De vítimas do poder transformam-se gradativamente em sujeitos de poder. A falta de uma tradição político-organizativa consolidada e o incentivo direto ou indireto do governo para solidificar sua base de apoio são motivos de tensões contínuas. O bolivarianismo como tendência radical de transformação social, dada a combinação desigual entre 
expressões reivindicativas e políticas, mesmo que anterior e para além do MBR-200, do MVR, do PSUV ou do chavismo, ainda é um processo em definição. Mas uma de suas maiores riquezas é, sem dúvida, a capacidade de ativar os conteúdos transformadores, nacionalistas e anticolonialistas de Bolívar e, assim, recriar o sujeito social da emancipação, expressando a possibilidade da síntese dialética entre o socialismo como forma. Ou seja, como ideal ou projeto de transformação radical com o conteúdo, no caso as especificidades históricas e sociais venezuelanas.

A princípio, o chavismo referia-se exclusivamente à responsabilidade de Chávez no levante militar de 1992, embora tenha sido executado pelo MBR-200. Ganha novos contornos quando a heterogeneidade do MVR confere a Chávez o fundamental papel mediador e diretivo. Assim, à medida que o processo avança, fazendo aumentar os enfrentamentos com a oposição e as contradições internas, o chavismo, ao mesmo tempo em que se torna garantia da continuidade e aprofundamento das mudanças sociais, também se transforma em elemento personalista e subordinador da autonomia e participação política. Não causa espanto que em determinados momentos o chavismo se confunda e até mesmo se choque com o bolivarianismo, entendido como a totalidade do processo em marcha.

Decorre daí que a simplificação dos processos sociopolíticos venezuelanos à capacidade individual da liderança de Chávez tende a associar o chavismo como manifestação do discurso populista. Seja de conteúdo radical ou demagógico, o que se defende neste texto é que, mais do que alguns elementos tomados à parte, o fenômeno populista corresponda a uma complexidade de fatores historicamente localizados.

As tensões entre autonomia e subordinação das bases bolivarianas, a redução das eleições e referendos entre o "contra" ou a "favor de Chávez", além das dificuldades em superar a propriedade e a divisão do trabalho capitalista, correm o risco de reduzir a democracia protagônica e popular, um dos elementos centrais do processo bolivariano, mais a um fim do que a um meio para a transformação social venezuelana.

\section{Referências}

CARRERA DAMAS, Germán. El bolivarianismo-militarismo: una ideología de reemplazo. Caracas: Ala del Cuervo, 2005.

CHÁVEZ, Hugo. Senderos de la via bolivariana. Caracas: Ediciones de la Presidencia de la República, 2007.

ELLNER, Steve. Las tensiones entre la base y la dirigencia en las filas del chavismo. Revista Venezoelana de Economia y Ciencias Sociales, Caracas, v. 14, n. 1, ene./abr. 2008.

. Hugo Chávez's first decade in office: breakthroughs and shortcomings. Latin American Perspectives, v. 37, n. 77, 2010.

GOTT, Richard. À sombra do Libertador. São Paulo: Expressão Popular, 2004.

HAWKINS, Kirk. Is Chávez populist? Measuring populist discourse in comparative perspective. Comparative Political Studies, v. 42, Feb. 2009.

IANNI, Octavio. A formação do Estado populista na América Latina. Rio de Janeiro: Civilização Brasileira, 1991.

LACLAU, Ernesto. La deriva populista y la centroizquierda latinoamericana. Nueva Sociedad, n. 205, 2006.

LANDER, Edgardo. El Estado y las tensiones de la participación popular en Venezuela. OSAL, Buenos Aires: CLACSO, año VIII, n. 22, sept. 2007.

. El referendum sobre la Reforma Constitucional: el processo político en Venezuela entra en una encrucijada crítica. Revista Venezoelana de Economia y Ciencias Sociales, Caracas, v. 14, n. 2, mayo/ago. 2008.
LÓPEZ-MAYA, Margarita. Protesta y cultura em Venezuela: los marcos de acción colectiva em 1999. Buenos Aires: Clacso, 2002.

. Hugo Chávez Frías: his moviment and his presidency. In: ELLNER, Steve; HELLINGER, Daniel. Venezuelan politics in the Chávez era. Colorado: Riener, 2003. Venezuela: Hugo Chávez y el bolivarianismo. Revista Venezoelana de Economia y Ciencias Sociales, Caracas, v. 14, n. 3, sept./dic. 2008.

LOVERA, Alberto. Los consejos comunales en Venezuela: democracia participativa o delegativa?. Revista Venezoelana de Economia y Ciencias Sociales, Caracas, v. 14, n. 1, ene./abr. 2008.

LYNCH, Nicolás. Neopopulismo: un concepto vacío. In: . Política y Antipolítica em Peru. Lima: Desco, 2000.

MARINGONI, Gilberto. A Venezuela que se inventa. São Paulo: Perseu Abramo, 2004.

. A revolução venezuelana. São Paulo: Edusp, 2009.

MONEDERO, Juan Carlos. Sobre el Partido Socialista Unido de Venezuela: potencialidades y riesgos In: LÓPEZ-MAYA, Margarita. Ideas para debatir el socialismo del siglo XXI, v. I. Caracas: Alfa, 2007.

NICANOFF, Sergio; STRATTA, Fernando. La revolución bolivariana: notas sobre la relación entre Estado y movimientos sociales. In: JORNADAS INTERNACIONALES DE PROBLEMAS LATINOAMERICANOS, Mar del Plata, sept. 2008. 
PARKER, Dick. El chavismo: populismo radical y potencial revolucionario. Revista Venezolana de Economía y Ciencias Sociales, Caracas, v. 7, n. 1, ene./abr. 2001.

REPÚBLICA BOLIVARIANA DE VENEZUELA. Constituición de la República Bolivariana de Venezuela. Caracas: Gaceta Oficial, 1999.

SALAZAR, Temístocles. Partido único, el reencuentro de Antígona y la distorsión del liderazgo." In: LÓPEZ-MAYA, Margarita. Ideas para debatir el socialismo del siglo XXI, v. I. Caracas: Alfa, 2007.

TOUSSAINT, Eric. Luces y sombras en la Venezuela bo- livariana, oct. 2009. Disponível em: <http://www.rebelion.org>. Acesso em: 13 nov. 2009.

VILAS, Carlos. ¿Populismos reciclados o neoliberalismo a secas? El mito del "neopopulismo" latinoamericano. Revista Venezolana de Economía y Ciencias Sociales, Caracas, v. 9, n. 3, mayo/ago. 2003.

WEFFORT, Francisco. O populismo na política brasileira. São Paulo: Paz e Terra, 2003.

ZEUSKE, Max. Simón Bolívar, su posición en la historia y en la actualidad. In: Interpretaciones y ensayos marxistas acerca de Simón Bolivar. Berlín: Akademie-Verlag, 1985.

\title{
The Venezuelan revolution: chavism and bolivarianism
}

\begin{abstract}
One of the most significant transformations since the beginning of the Bolivarian Government in 1999 is that political participation is no longer a mere form, but has instead become a reality. The term chavism is shown many times as a descriptive synthesis of the whole sum of processes of social changes, which has granted it the populist insignia. Even though it is important to understand the Bolivarian revolution, the focus on the "Chavez phenomena" hides the importance of the relationship between mobilization and social organizations to push and sustain the process. The aim of this article is to outline the concrete distances between chavism, bolivarianism and populism. In that sense, we start from the evaluation of the recent transformations in Venezuela, not only those which involve the political instruments managed by Chávez, but also those of the inferior classes who start to express themselves politically throughout the decade of 1990.
\end{abstract}

Key words: Chavism, bolivarianism, populism, Venezuela

\section{La revolución venezoelana: chavismo y bolivarianismo}

\section{Resumen}

Una de las transformaciones más significativas desde el inicio del gobierno bolivariano en 1999 es que la participación política, más que mera formalidad, tiene si convertido en realidad. El termino chavismo parece muchas veces como síntesis descriptiva de la totalidad de estos procesos de mudanza social, hecho que tiene le rendido a insignia populista. A pesar de importante para la comprensión de la revolución bolivariana, al centrar sus atenciones sobre el "fenómeno Chávez", ignorase la importancia de las relaciones entre movilizaciones y organizaciones sociales para impulsar y sustentar el proceso. El objetivo de este artículo es delimitar las distancias concretas entre chavismo, bolivarianismo y populismo. Para eso, partimos de la evaluación de las transformaciones recientes en Venezuela, tanto las que envuelven los instrumentos políticos dirigidos por Chávez, como también de las clases subalternas que empiezan a manifestarse políticamente al largo de la década de 1990.

Palabras clave: Chavismo, bolivarianismo, populismo, Venezuela

Data de recebimento do artigo: 26/3/2010

Data de aprovação do artigo: 18/6/2010 